\title{
Seleção de cultivares de sorgo e braquiária em consórcio para produção de grãos e palhada
}

\section{Selection of sorghum and brachiaria cultivars in intercropping for straw and grains production}

\author{
Alessandro Guerra da Silva ${ }^{1 *}$; Adalbert Horvath $\mathrm{Neto}^{2}$; Itamar Rosa Teixeira ${ }^{3}$; \\ Kátia Aparecida Pinho da Costa ${ }^{4}$; Alessandro Lucca Braccini ${ }^{5}$
}

\section{Resumo}

O consórcio de sorgo com braquiária apresenta potencial para produção de grãos e palhada. Porém, poucos estudos têm sido realizados no intuito de selecionar cultivares para o consórcio, em condições de safrinha, na região Centro-Oeste. O objetivo deste trabalho foi selecionar cultivares de sorgo granífero e espécies de braquiárias em consórcio na linha, em safrinha, visando produção de grãos e palhada. O ensaio foi realizado em Rio Verde-GO, na safrinha de 2010. O delineamento experimental utilizado foi o de blocos casualizados, em esquema fatorial $2 \times 5+2+5$ correspondendo a duas cultivares de sorgo granífero (BRS 310 e DKB 599) consorciadas na linha com cinco cultivares de braquiária (Brachiaria brizantha cv. Xaraés, Marandu e Piatã, $B$. decumbens e B. ruziziensis). Adicionalmente, efetuaram-se sete tratamentos adicionais referentes aos monocultivos das duas cultivares de sorgo e cinco de braquiária. Os resultados permitiram constatar que os consórcios do BRS $310 \mathrm{com}$ a B. ruziziensis e B. brizantha cv. Xaraés proporcionaram maiores rendimentos de grãos, massa seca (palhada) e proteína bruta total, sendo o mesmo constatado para o DKB 599 consorciado com a $B$. decumbens. O híbrido DKB 599 apresentou maior potencial produtivo, porém, maior sensibilidade a competição com as plantas de braquiária. Em determinados tratamentos, a braquiária ocasionou redução do estande do sorgo e, consequemente, diminuição do rendimento de grãos. O consórcio de sorgo granífero e braquiária na safrinha mostrou-se como técnica de cultivo viável para produção de grãos e palhada na região Centro-Oeste.

Palavras-chave: Sorghum bicolor, forragem, plantio direto, safrinha, sucessão de culturas, conservação do solo

\begin{abstract}
The sorghum and brachiaria intercropping shows potential to produce grains and straw. However, few studies have been made to select cultivars for the intercropping conditions, in off-season cultivation, at Central-West region of Brazil. The objective of this study was to select sorghum and brachiaria cultivars intercropped in the row, in off-season cultivation, to obtain grains and straw. The experimental was carried out at Rio Verde-GO in the 2010 off-season cultivation. The experimental design was the randomized blocks, in scheme factorial $2 \times 5+2+5$ corresponding to two cultivars of grain sorghum (BRS 310 and DKB 599) intercropped in the row with five brachiaria cultivars (Brachiaria brizantha $\mathrm{cv}$.
\end{abstract}

1 Prof. Adjunto, Universidade de Rio Verde, UniRV, Rio Verde, GO. Bolsista de Produtividade em Pesquisa 2 do CNPq. E-mail: silvaag@yahoo.com.br

2 Discente, Programa de Pós-graduação em Produção Vegetal, UniRV, Rio Verde, GO. E-mail: adalberthorvathy@hotmail.com

3 Prof. Adjunto, Universidade Estadual de Goiás, UEG, Anápolis, GO. Bolsista de Produtividade em Pesquisa 2 do CNPq. E-mail: itamar.texeira@ueg.br

${ }^{4}$ Profa ${ }^{a}$ Classe III Nível 4, Instituto Federal Goiano, Campus Rio Verde, Rio Verde, GO. Bolsista de Extensão no País B pelo CNPq. E-mail:katiazoo@hotmail.com

5 Prof. Associado, Universidade Estadual de Maringá, UEM, Maringá, PR. Bolsista de Produtividade em Pesquisa 1A do CNPq. E-mail: albraccini@uol.com.br

* Autor para correspondência 
Xaraés, Marandu and Piatã, B. decumbens and B. ruziziensis). Additionally, it was carried out seven additional treatments related to monocultures of the two sorghum cultivars and five of the brachiaria. The results demonstrated that the sorghum BRS 310 intercropped with B. ruziziensis and B. brizantha Xaraés provided higher total crude protein, dry matter (straw) and grain yields, being the same fact observed for the DKB 599 intercropped with the B. decumbens. The hybrid DKB 599 showed higher yield potential, but also greater sensitivity to competition with the brachiaria plants. In certain treatments, the brachiaria crop caused reduction of sorghum stand, and thus, decreased the grain yield. The grain sorghum and brachiaria intercropping, in off-season cultivation, shows to be a viable growth technique to produce grains and straw in the Central-West region of Brazil.

Key words: Sorghum bicolor, forage, no-tillage, off-season cultivation, crop succession, soil conservation

\section{Introdução}

Na região Centro-Oeste a cultura do sorgo temse destacado na produção de grãos sendo implantada após a colheita da soja em solos cultivados no sistema plantio direto. A preferência pelo sorgo deve-se a crescente demanda por grãos para atender a fabricação de ração nas agroindústrias instaladas na região, visto que o custo da aquisição dos grãos é menor quando comparado ao milho. Além disto, a limitação da produção deste cereal em determinados anos em função da menor disponibilidade de chuvas ou em semeaduras tardias tem levado os produtores a optarem pelo sorgo granífero no cultivo de safrinha.

No sistema de produção agrícola do CentroOeste, uma dificuldade que os produtores rurais têm enfrentado no plantio direto é a manutenção da palhada na superfície do solo no período de entressafra (KLIEMANN; BRAZ; SILVEIRA, 2006; BORGHI; CRUSCIOL, 2007). Neste contexto, as culturas de safrinha são fundamentais para a implantação e viabilização do sistema, por proporcionarem cobertura do solo por maior tempo, diversificação das receitas da propriedade e diminuição dos riscos com a atividade agrícola. Assim, a cultura do sorgo torna-se uma excelente opção em relação ao milho para produção de grãos no Centro-Oeste (SILVA et al., 2009a), pois além de produzir palhada na entressafra, a cultura adaptase a vários ambientes (BAUMHARDT; TOLK; WINTER, 2005; DAN et al., 2010), expandindo assim seu cultivo para várias regiões de produção de grãos na safrinha.
As gramíneas forrageiras, como as braquiárias destacam-se como alternativas para adoção nos sistemas de rotação, sucessão ou consorciação de culturas no cerrado. O consórcio de sorgo com Brachiaria brizantha cv. Marandu tem-se mostrado como prática viável de cultivo agrícola (MELLO et al., 2004), além do fato de que o manejo de ervas daninhas na cultura em sucessão é facilitado pela produção de palhada de sorgo (SOUZA; SOUZA; PASQUAL, 1999) e Brachiaria brizantha (MACHADO et al., 2011) na superfície do solo.

Porém, em regiões produtoras de grãos do Brasil Central, muitos produtores têm receio em adotar o sistema integração lavoura-pecuária de sorgo com braquiária, devido à ausência de informações a respeito da escolha correta de cultivares e do manejo das culturas em consórcio. Destaca-se que a adoção deste sistema na safrinha possibilita a produção de grãos de sorgo e posteriormente, de palhada das culturas do sorgo e braquiária. Estas poderão ser usadas para pastejo e/ou cobertura do solo no período da entressafra. Desta forma, além da produção de grãos e de palhada, o consórcio destas espécies na safrinha torna-se opção interessante para adoção da sucessão e rotação de culturas em solos cultivados no sistema plantio direto.

Portanto, o objetivo deste trabalho é o de selecionar, em condições de consórcio na safrinha, cultivares de sorgo granífero e braquiária que proporcionem maiores rendimentos de grãos e palhada para cobertura do solo na região CentroOeste. 


\section{Material e Métodos}

O trabalho foi conduzido a campo $\left(17^{\circ} 47^{\prime} 24,5^{\prime \prime} \mathrm{S}\right.$; $50^{\circ} 57^{\prime} 41,7^{\prime}$ 'W e $769 \mathrm{~m}$ de altitude) na safrinha de 2010, em Rio Verde-GO em Latossolo Vermelho distrófico, cultivado no sistema de semeadura direta, com cultivo de soja na safra anterior. Os resultados da análise química da amostra de solo da área experimental foram: $\mathrm{pH}$ em $\mathrm{CaCl}_{2}$ : 4,2; $\mathrm{Ca}$,
$\mathrm{Mg}, \mathrm{K}, \mathrm{Al}, \mathrm{H}+\mathrm{Al}, \mathrm{CTC}$ e SB: 1,$30 ; 0,87 ; 0,30 ; 0,50$; 6,$4 ; 8,91$ e 2,47 em cmol $\mathrm{dm}^{-3}$, respectivamente; P: 4,13 $\mathrm{mg} \mathrm{dm}^{-3}$; saturação de bases e de alumínio: 27,72 e 16,83\%, respectivamente; $\mathrm{Cu}, \mathrm{Zn}$, Fe e $\mathrm{Mn}$ : 5,5; 2,2; 99,0 e 186,0 em mg dm${ }^{-3}$, respectivamente; matéria orgânica: $35,94 \mathrm{~g} \mathrm{dm}^{-3}$; argila, silte e areia: 580; 120 e $300 \mathrm{~g} \mathrm{~kg}^{-1}$, respectivamente. As variações de temperatura média do ar e precipitação durante a condução do ensaio são apresentadas na Figura 1.

Figura 1. Variação mensal da temperatura média do ar e precipitação pluvial de janeiro a dezembro de 2010, Estação Climatológica da Universidade de Rio Verde, Rio Verde-GO.

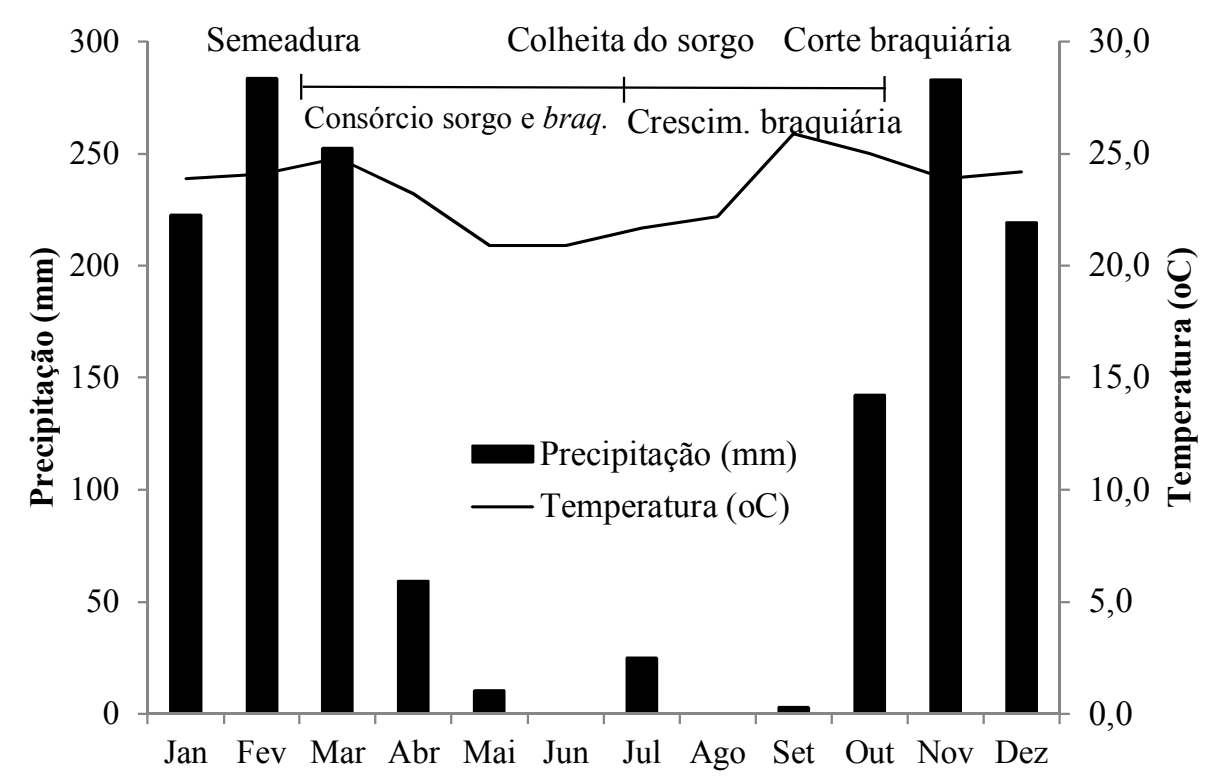

Fonte: Elaboração dos autores.

O delineamento experimental adotado foi o de blocos casualizados, em esquema fatorial $2 \times 5+2+5$, com quatro repetições, correspondendo a dois híbridos de sorgo granífero (BRS 310 e DKB 599; ambos precoces, de grãos vermelhos e sem tanino) consorciados na linha com cinco espécies de braquiária ( $B$. brizantha cultivares Marandu, Xaraés, Piatã, Brachiaria decumbens e B. ruziziensis). Adicionalmente, implantaram-se sete tratamentos, na mesma época do consórcio, também, em blocos casualizados com quatro repetições, referentes aos monocultivos do sorgo granífero e das cinco cultivares de braquiárias. Estes tinham como objetivo a comparação da eficiência do consórcio em relação aos monocultivos das espécies consorciadas. As parcelas foram constituídas de sete linhas de semeadura do sorgo, com 5,0 m de comprimento, espaçadas $0,45 \mathrm{~m}$ entre si. A área útil foi obtida desconsiderando as duas linhas laterais e eliminando-se $0,5 \mathrm{~m}$ de cada extremidade $\left(5,4 \mathrm{~m}^{2}\right)$.

Uma semana antes da implantação do ensaio foi realizada a dessecação das ervas daninhas empregando-se, mecanicamente, o equivalente a 1.440 g e.a. ha ${ }^{-1}$ de glifosato e 433,5 g i.a. ha- ${ }^{-1}$ de 2,4 D, em um volume de calda de $150 \mathrm{~L} \mathrm{ha}^{-1}$. Para a semeadura, efetuou-se a adubação dos sulcos da 
área experimental com $313 \mathrm{~kg} \mathrm{ha}^{-1}$ do fertilizante 02-20-18.

As semeaduras de ambas as culturas foram realizadas, manualmente, no dia 25 de fevereiro. A braquiária foi semeada a $10 \mathrm{~cm}$ de profundidade, com auxílio de um gabarito graduado, sendo colocadas junto com o fertilizante, e o sorgo a $2 \mathrm{~cm}$ de profundidade. No monocultivo, as duas espécies foram semeadas a $2 \mathrm{~cm}$ de profundidade. Para definição da quantidade de sementes de braquiária, levou-se em consideração o valor cultural ((240 $\mathrm{VC}^{-1}$ ) das sementes (B. brizantha: cv. Xaraés: 38\%; Marandu: 60\%; Piatã: 53\%; B ruziziensis: 75,6\%; $B$. decumbens: 50\%), obtendo-se a quantidade equivalente em $\mathrm{kg} \mathrm{ha}^{-1}$.

Aos 15 dias após a emergência das plântulas de sorgo (DAE), foi realizado o desbaste das plantas em consórcio e no monocultivo, deixando população equivalente a 180.000 plantas $\mathrm{ha}^{-1}$. Aos $20 \mathrm{DAE}$ foram aplicados, ao lado da linha de semeadura, 100 $\mathrm{kg} \mathrm{ha}^{-1}$ de $\mathrm{N}$ na forma de uréia.

Para o controle das ervas daninhas em pósemergência foram realizadas três capinas manuais até aos 30 DAE. Na fase de emborrachamento do sorgo e para evitar problemas com Spodoptera frugiperda, foi realizada, de forma mecanizada, a aplicação de 50 g i.a. ha ${ }^{-1}$ de cipermetrina, com volume de calda de $150 \mathrm{~L} \mathrm{ha}^{-1}$.

Aos 119 DAE, foi realizada a colheita do sorgo, sendo avaliadas, na área útil da parcela, as seguintes características: rendimento de grãos (colheita das panículas, com posterior debulha e pesagem dos grãos, com correção da umidade para 13\%); peso de 1.000 grãos (determinação do peso de mil grãos, escolhidos aleatoriamente na amostra de rendimento, com correção da umidade para 13\%); altura de plantas (medição do colo até a extremidade da panícula em cinco plantas escolhidas aleatoriamente); índice de perfilhamento (contagem do número de perfilhos em cinco plantas escolhidas aleatoriamente); e estande final (contagem do número total de plantas colhidas).
Após a colheita do sorgo, as braquiárias permaneceram mais 131 dias no campo, sendo realizadas as seguintes avaliações: altura das plantas (medição, em cinco plantas escolhidas aleatoriamente, do colo até a extremidade da última folha completamente expandida) e o índice de perfilhamento (contagem do número de perfilhos em cinco plantas escolhidas aleatoriamente).

Também foram avaliados, para cada cultura, o rendimento de massa seca total - palhada (coleta em $1 \mathrm{~m}^{2}$ da massa vegetal do sorgo e braquiária, por meio de um quadrado de ferro de dimensões de 1,0 x 1,0 m, com o corte feito rente ao solo; as amostras foram acondicionadas separadamente em sacos de papel e levadas para secagem em estufa a $65{ }^{\circ} \mathrm{C}$, determinando o peso seco e, em seguida, o rendimento de massa seca total, expressando os resultados em $\mathrm{kg} \mathrm{ha}^{-1}$ ) e rendimento de proteína bruta total (as amostras de massa seca foram moídas em moinho do tipo Willey, com peneira de $1 \mathrm{~mm}$ de diâmetro, determinando, posteriormente, o teor de $\mathrm{N}$ pelo método microKjeldahl; os resultados obtidos foram multiplicados por 6,25 para se obter o teor de proteína bruta (MALAVOLTA; VITTI; OLIVEIRA, 1997) de cada espécie; em seguida efetuou-se o produto do rendimento de massa seca pelo teor de proteína bruta para cada espécie e, então, somados para obtenção do rendimento de proteína bruta total, expressos em $\mathrm{kg} \mathrm{ha}^{-1}$ ).

Para cada espécie, na mesma época, quantificouse também a relação $\mathrm{C} / \mathrm{N}$ da massa vegetal (determinação do $\mathrm{C}$ orgânico pela queima das amostras em mufla à $550{ }^{\circ} \mathrm{C}$ (EMBRAPA, 1997) e o $\mathrm{N}$ pelo método microKjeldahl, como relatado anteriormente, obtendo posteriormente a relação $\mathrm{C} / \mathrm{N}$ de cada espécie). Logo após a colheita do sorgo, quantificou-se a porcentagem de cobertura vegetal sobre o solo (avaliação em dois pontos escolhidos aleatoriamente na área útil da parcela, com utilização de um quadrado de ferro de dimensões de $0,5 \times 0,5 \mathrm{~m}$, contendo uma linha com dez pontos separados equidistantes; a determinação da porcentagem de cobertura na superfície do solo 
foi computada quando esses pontos coincidiam com a presença de cobertura vegetal). A eficiência do consórcio foi avaliada pelo índice de equivalência de área (somatório das relações do rendimento de grãos do sorgo obtidos no consórcio e monocultivo acrescido da relação do rendimento de massa seca total do consórcio e monocultivo de braquiária).

A análise estatística foi realizada pelos programas estatísticos Sisvar e Genes. Em uma primeira etapa, realizou-se a análise de variância individual e em seguida à análise combinada entre o consórcio e o monocultivo. Para a comparação das médias obtidas no consórcio e no monocultivo, empregou-se, quando constatada significância para determinada fonte de variação, o teste de Tukey a 5\% de probabilidade. Entre o consórcio e o monocultivo (testemunhas), realizou-se a comparação das médias por meio de contrastes pelo teste de Dunnett a $5 \%$ de probabilidade. Na análise do IEA, em que os valores obtidos são oriundas do consórcio e monocultivo, empregou-se o esquema fatorial simples $2 \times 5$, referentes as duas cultivares de sorgo e cinco de braquiária, com as médias comparadas pelo teste de Tukey a $5 \%$.

\section{Resultados e Discussão}

\section{Cultura do sorgo}

Os resultados da análise de variância constataram significância para as variáveis rendimento de grãos (Braquiária, Sorgo x Braquiária, Monocultivo e Consórcio x Monocultivo), peso de mil grãos e altura de plantas (Sorgo e Consórcio x Monocultivo), estande (Sorgo x Braquiária e Consórcio x Monocultivo) e relação C/N (Sorgo, Braquiária e Consórcio x Monocultivo), não havendo significância para o índice de perfilhamento (Tabela 1). Em contrapartida, não foi constatado acamamento das plantas do sorgo no consórcio e no monocultivo.
A avaliação do rendimento de grãos permitiu constatar que, para cada espécie de braquiária, o sorgo DKB 599 apresentou maior rendimento de grãos em relação ao BRS 310 quando consorciado com a $B$. decumbens, ocorrendo o inverso para a $B$. ruziziensis (Tabela 2). Para as cultivares de $B$. brizantha (cvs. Xaraés, Marandu e Piatã), não foram constatadas diferenças significativas de rendimento entre os híbridos de sorgo. Pode-se inferir que, mesmo sendo semeadas a $10 \mathrm{~cm}$ de profundidade, a $B$. decumbens e a $B$. ruziziensis foram as espécies que exerceram maior competição por água, luz, nutrientes e espaço físico com os híbridos BRS 310 e DKB 599, respectivamente, visto que ambas espécies foram consorciadas na mesma linha de semeadura. Destaca-se que o solo da área experimental apresenta baixa saturação de bases, o que favoreceu o desenvolvimento da $B$. decumbens (VILELA et al., 1998), ocasionando assim maior competição com o sorgo BRS 310 . Associado a baixa saturação de bases e o fato de ser mais exigente em fertilidade do solo em relação ao BRS 310, o sorgo DKB 599 apresentou maior sensibilidade a competição com as plantas de $B$. ruziziensis, ocasionando consequentemente redução do rendimento de grãos.

É importante destacar que o sorgo BRS 310, cultivado na safrinha em consórcio na linha com a $B$. ruziziensis possibilitou a obtenção de maior rendimento de grãos, seguido do consórcio com a $B$. brizantha cv. Xaraés (Tabela 2). Para o DKB 599, a associação com a $B$. decumbens foi a que proporcionou maior rendimento, seguida da $B$. brizantha cv. Xaraés. As maiores reduções no rendimento dos sorgos BRS 310 e DKB 599 foram constatadas com a B. brizantha cv. Marandu, demonstrando a maior competição das plantas dessa espécie de braquiária com as de sorgo. 
Tabela 1. Resultados da análise de variância das variáveis rendimento (RG) e peso de mil grãos (PMG), altura de plantas (APS), índice de perfilhamento (IPS), estande (EST) e relação $\mathrm{C} / \mathrm{N}(\mathrm{C} / \mathrm{N})$ da cultura do sorgo, altura de plantas (APB), índice de perfilhamento (IPB) e relação $\mathrm{C} / \mathrm{N}(\mathrm{C} / \mathrm{N})$ da braquiária, rendimentos de massa seca (RMST) e proteína bruta total (RPBT), cobertura do solo (CS) e índice de equivalência de área (IEA) do consórcio na linha de híbridos de sorgo granífero e espécies de braquiária na safrinha, Rio Verde-GO.

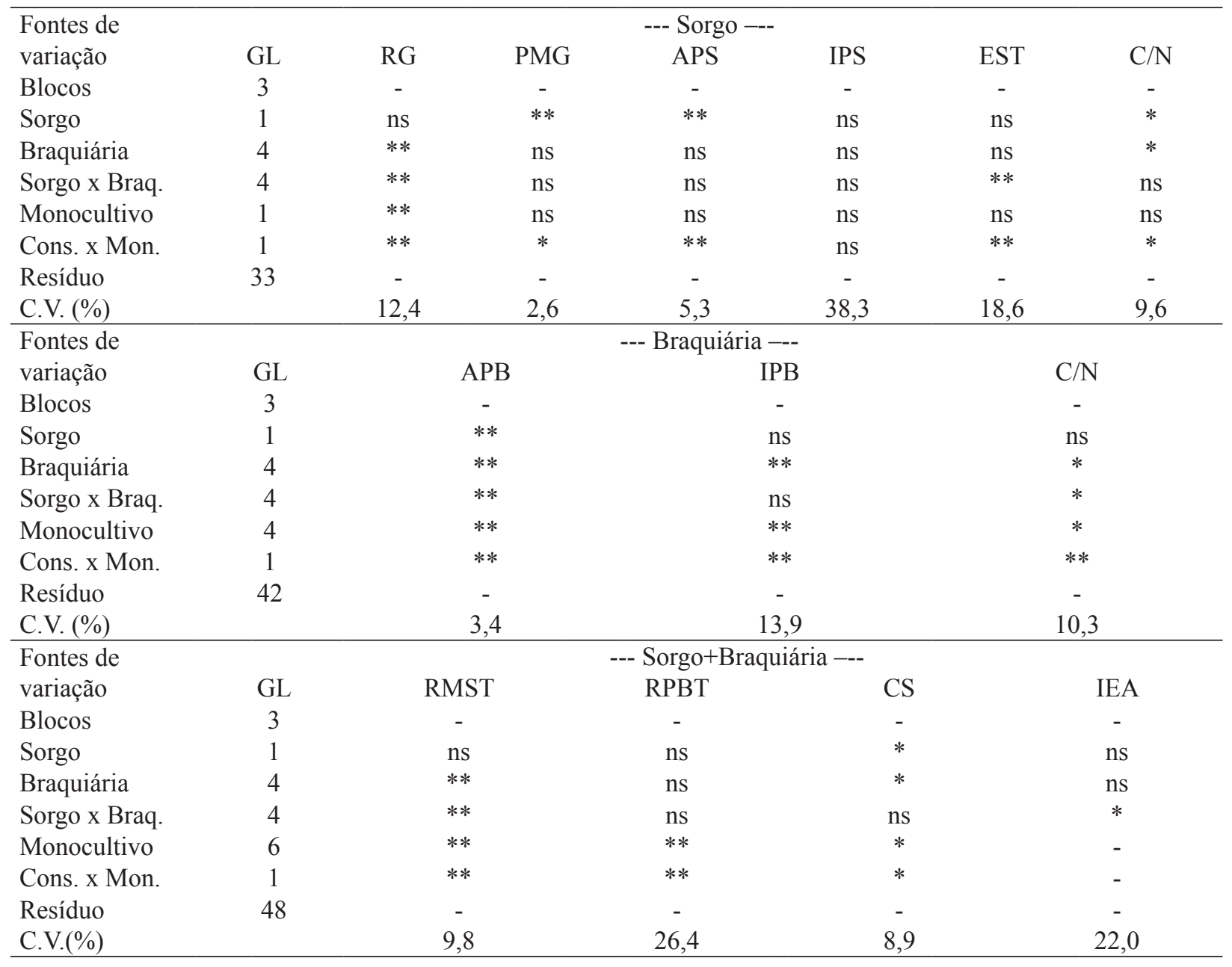

*** e ns: Significativo a 1 e a $5 \%$ de probabilidade e não significativo pelo teste $\mathrm{F}$, respectivamente.

Fonte: Elaboração dos autores.

O consórcio do BRS 310 com a B. ruziziensis e $B$. brizantha $\mathrm{cv}$. Xaraés não ocasionou redução no rendimento de grãos em relação ao monocultivo do sorgo (Tabela 2). Nas demais combinações, houve reduções expressivas do rendimento do BRS 310 . Já o híbrido DKB 599, por ser mais exigente em fertilidade de solo e apresentar maior potencial produtivo em relação ao BRS 310, comprovado nos resultados do monocultivo, apresentou redução no rendimento em todas as associações com braquiária (resultados inferiores ao monocultivo do DKB 599). Isto é atribuído à competição das plantas de sorgo com a braquiária, pois somente o sorgo foi adubado e o consórcio foi realizado na mesma linha de semeadura. Além disto, pode-se verificar que o híbrido de maior potencial produtivo (DKB 599) foi mais sensível à competição quando consorciado com as espécies de braquiária. Mesmo com reduções do rendimento no consórcio, os resultados permitem comprovar o potencial do uso deste sistema de cultivo na safrinha, sendo os valores superiores aos de Silva et al. (2009a) com o cultivo de diferentes híbridos de sorgo granífero em sucessão a soja na mesma região de realização do ensaio. 
Tabela 2. Valores médios de rendimento (RG) e peso de mil grãos (P1000), altura de plantas (APS), estande (EST), relação $\mathrm{C} / \mathrm{N}(\mathrm{C} / \mathrm{N})$ e índice de perfilhamento (IPS) dos sorgos graníferos BRS 310 e DKB 599 consorciados na linha com $B$. brizantha cv. Xaraés, cv. Marandu e cv. Piatã, B. decumbens $(B d)$ e B. ruziziensis $(B r)$ e em monocultivo na safrinha, Rio Verde-GO ${ }^{1 /}$.

\begin{tabular}{|c|c|c|c|c|c|c|}
\hline Consórcio & Xaraés & Marandu & Piatã & $B d$ & $B r$ & Médias \\
\hline \multicolumn{7}{|c|}{$\mathrm{RG}\left(\mathrm{t} \mathrm{ha}^{-1}\right)$} \\
\hline BRS 310 & 3,6 $\mathrm{Aab}^{* 2}$ & $2,6 \mathrm{Ac}^{* 1,2}$ & $2,8 \mathrm{Abc}^{* 1,2}$ & $2,8 \mathrm{Bbc}^{* 1,2}$ & $4,2 \mathrm{Aa}^{* 2}$ & 3,2 \\
\hline DKB 599 & $3,4 \mathrm{Ab}^{* 2}$ & $2,4 \mathrm{Ac}^{* 1,2}$ & $3,1 \mathrm{Abc}^{* 1,2}$ & $4,2 \mathrm{Aa}^{* 2}$ & $3,1 \mathrm{Bbc}^{* 1,2}$ & 3,2 \\
\hline Médias & $3,5 \mathrm{ab}$ & $2,5 \mathrm{c}$ & $2,9 \mathrm{bc}$ & $3,5 \mathrm{ab}$ & $3,7 \mathrm{a}$ & \\
\hline \multirow[t]{2}{*}{ Monocultivo } & & BRS 310 & & DKB 599 & & \\
\hline & & $4,1 \mathrm{~b}$ & & $5,3 \mathrm{a}$ & & \\
\hline \multicolumn{7}{|c|}{$\mathrm{P} 1000(\mathrm{~g})$} \\
\hline BRS 310 & $13,1 * 2$ & $13,0 * 2$ & $13,2 * 2$ & $13,2 * 2$ & $13,2 * 2$ & $13,1 \mathrm{~b}$ \\
\hline DKB 599 & 13,9 & 14,2 & 13,9 & 14,1 & 14,1 & $14,0 \mathrm{a}$ \\
\hline Médias & 13,5 & 13,6 & 13,5 & 13,6 & 13,7 & \\
\hline \multirow[t]{2}{*}{ Monocultivo } & & BRS 310 & & DKB 599 & & \\
\hline & & 13,7 & & 14,2 & & \\
\hline \multicolumn{7}{|c|}{ APS (cm) } \\
\hline BRS 310 & 1,1 & 1,1 & 1,1 & 1,1 & 1,1 & $1,1 \mathrm{~A}$ \\
\hline DKB 599 & $0,9 * 1,2$ & $1,0 * 1,2$ & $1,0 * 1,2$ & $1,0 * 1,2$ & $1,0 * 1,2$ & $1,0 \mathrm{~B}$ \\
\hline Médias & 1,0 & 1,1 & 1,1 & 1,1 & 1,1 & \\
\hline \multirow[t]{2}{*}{ Monocultivo } & & BRS 310 & & DKB 599 & & \\
\hline & & 1,2 & & 1,2 & & \\
\hline \multicolumn{7}{|c|}{ EST (x 10.000 pls ha $\left.^{-1}\right)$} \\
\hline BRS 310 & 19,8 Aab & $15,3 \mathrm{Aab}^{* 1,2}$ & $15,3 \mathrm{Aab}^{* 1,2}$ & $14,0 \mathrm{Bb}^{* 1,2}$ & $20,4 \mathrm{Aa}$ & 16,9 \\
\hline DKB 599 & $18,3 \mathrm{Aab}$ & $15,1 \mathrm{Ab}^{* 1,2}$ & $16,8 \mathrm{Aab}^{* 2}$ & $21,8 \mathrm{Aa}$ & $16,8 \mathrm{Aab}^{* 2}$ & 17,8 \\
\hline Médias & 19,1 & 15,2 & 16,1 & 18,0 & 18,6 & \\
\hline \multirow{2}{*}{ Monocultivo } & & BRS 310 & & DKB 599 & & \\
\hline & & 22,2 & & 23,7 & & \\
\hline \multicolumn{7}{|c|}{$\mathrm{C} / \mathrm{N}$} \\
\hline BRS 310 & $70 * 1,2$ & $76^{* 1,2}$ & $79 * 1,2$ & $71 * 1,2$ & $75^{* 1,2}$ & $74 \mathrm{~A}$ \\
\hline DKB 599 & $61 * 2$ & $74 * 1,2$ & $79 * 1,2$ & $70 * 1,2$ & $63^{* 2}$ & $69 \mathrm{~B}$ \\
\hline & $65 \mathrm{~b}$ & $75 a b$ & $79 \mathrm{a}$ & $71 \mathrm{ab}$ & $69 a b$ & \\
\hline \multirow{2}{*}{ Monocultivo } & & BRS 310 & & DKB 599 & & \\
\hline & & 66 & & 62 & & \\
\hline IPS (\%) & & BRS 310 & & DKB 599 & & \\
\hline Consórcio & & 2,5 & & 2,8 & & \\
\hline Monocultivo & & 2,6 & & 3,0 & & \\
\hline
\end{tabular}

${ }^{11}$ : Médias seguidas pela mesma letra maiúscula na coluna e minúscula na linha não diferem entre si pelo teste de Tukey a $5 \%$ de probabilidade.

*1, *2: Média difere significativamente pelo teste de Dunnett a 5\% de probabilidade em relação aos sorgos graníferos BRS 310 e DKB 599, respectivamente.

Fonte: Elaboração dos autores.

O maior peso de mil grãos do híbrido $\mathrm{DKB}$ 599 no consórcio em relação ao BRS 310, em geral, não contribuiu para obtenção de maiores rendimentos (ausência de diferença significativa no rendimento médio de grãos dos híbridos no consórcio). Adicionalmente, não foram constatadas diferenças significativas para o peso de mil grãos no monocultivo e na comparação do consórcio com os respectivos monocultivos de sorgo (Tabela 2). Devido à competição por água com as plantas 
de braquiária no consórcio, os híbridos de sorgo apresentaram valores de peso de mil grãos inferiores aos de outros trabalhos de pesquisa com cultivo de sorgo (monocultivo) na safrinha na região CentroOeste (SILVA et al., 2009a).

A maior sensibilidade do DKB 599 à competição com as plantas de braquiária pode ser novamente comprovada pela avaliação da altura de plantas. No consórcio, em geral, o referido sorgo apresentou menor porte em relação ao BRS 310, como também em todas as combinações do consórcio do DKB 599 com o respectivo monocultivo (Tabela 2). Destacase que nesta condição de cultivo, não houve diferença significativa entre a altura de plantas entre os dois híbridos, comprovando o efeito supressor das plantas de braquiária no consórcio com o DKB 599.

A análise do estande de plantas na colheita do sorgo foi essencial para comprovar o efeito supressor das plantas de braquiária à cultura do sorgo. Neste contexto, observou-se que a $B$. decumbens, devido apresentar melhor performance em solos de menor fertilidade (VILELA et al., 1998), foi a única espécie que ocasionou diferenças significativas no estande do sorgo, com menor observado para o híbrido BRS 310 (Tabela 2). Isto, consequentemente, ocasionou redução no rendimento de grãos em relação ao híbrido DKB 599. Para as demais espécies de braquiárias, não foram constatadas diferenças significativas de estande entre os sorgos, o mesmo sendo observado no monocultivo.

Quando se comparam o estande do sorgo em consórcio com o do monocultivo, obtiveram-se menores valores no consórcio com as associações do BRS 310 com a B. brizantha cv. Marandu e Piatã e com a $B$. decumbens (Tabela 2). Resultados semelhantes foram também constatados para o DKB 599 consorciado com os mesmos cultivares de $B$. brizantha e $B$. ruziziensis, demonstrando o efeito da competição destas espécies no consórcio. Em contrapartida, ausência de diferenças significativas entre os sistemas de cultivo puderam ser constatadas com o DKB 599 consorciado com a $B$. decumbens e do BRS 310 com a B. ruziziensis, como observado para o rendimento de grãos. Portanto, conclui-se que associações com braquiária que não ocasionem redução do estande do sorgo é fundamental para obtenção de maiores rendimentos de grãos.

As relações $\mathrm{C} / \mathrm{N}$ do sorgo em todas as associações do consórcio foram superiores quando comparados aos monocultivos, sendo o BRS 310 de maior valor em relação ao DKB 599 na média do consórcio (Tabela 2). Os maiores valores no consórcio podem ser atribuídos a menor disponibilidade de nitrogênio para as plantas de sorgo em função da absorção pelas plantas de braquiária, visto que o consórcio foi realizado na mesma linha de semeadura. Neste sistema de cultivo, a associação com a $B$. brizantha cv. Piatã proporcionou maior valor em relação a $B$. brizantha cv. Xaraés. Outros trabalhos de pesquisa têm constatados, para o sorgo BRS 800 (corte e pastejo), relação $\mathrm{C} / \mathrm{N}$ de 55 a 100 (SILVA et al., 2009b; CALVO; FOLONI; BRANCALIÃO, 2010). Maior valor da relação $\mathrm{C} / \mathrm{N}$ torna-se vantajoso quando se deseja aumentar o tempo de permanência da palha na superfície do solo (KLIEMANN; BRAZ; SILVEIRA, 2006).

$\mathrm{Na}$ avaliação do índice de perfilhamento, não foram constatadas diferenças significativas entre as fontes de variação e os tratamentos empregados. Isto pode ser atribuído, provavelmente, ao atraso do desenvolvimento das braquiárias em relação ao sorgo em função da semeadura em maior profundidade $(10 \mathrm{~cm})$, não influenciando assim no perfilhamento.

\section{Cultura da braquiária}

A avaliação das características da braquiária permitiu constatar significâncias em todas as fontes de variação para as variáveis altura de plantas e relação $\mathrm{C} / \mathrm{N}$ (exceto para a fonte de variação Sorgo), bem como para os efeitos de Braquiária, Monocultivo e Consórcio $x$ Monocultivo na avaliação do índice de perfilhamento (Tabela 1). 
A competição entre plantas das espécies consorciadas pode ser comprovada também na avaliação das características da braquiária. Sendo assim o sorgo BRS 310 influenciou negativamente a altura de plantas da $B$. brizantha cv. Xaraés e Piatã e B. decumbens, pois os valores obtidos foram inferiores aos do consórcio com o DKB 599 (Tabela 3). Constatou-se também que a $B$. brizantha cv. Piatã e $B$. decumbens apresentaram maiores alturas em relação às demais espécies quando consorciadas com cada híbrido de sorgo. Os maiores valores são justificados pelo maior porte da $B$. brizantha cv. Piatã, observado também na média geral do consórcio e em monocultivo, e pela melhor performance da $B$. decumbens em solos de menor fertilidade (VILELA et al., 1998). Além disto, o ostiolamento das plantas de braquiária, em função do sombreamento exercido pelas plantas de sorgo no consórcio, ocasionou maior altura de plantas.

Tabela 3. Valores médios de altura (APB), índice de perfilhamento (IPB) e relação C/N (C/N) das espécies $B$. brizantha cv. Xaraés (Xaraés), cv. Marandu (Marandu) e cv. Piatã (Piatã), B. decumbens $(B d)$ e B. ruziziensis (Br) consorciadas na linha com os sorgos graníferos BRS 310 e DKB 599 e em monocultivo na safrinha, Rio Verde-GO ${ }^{11}$.

\begin{tabular}{|c|c|c|c|c|c|c|}
\hline Consórcio & Xaraés & Marandu & Piatã & $B d$ & $B r$ & Médias \\
\hline & & & $\mathrm{APB}(\mathrm{m})$ & & & \\
\hline BRS 310 & $0,59 \mathrm{Bb}^{*}$ & $0,63 \mathrm{Ab}$ & $0,73 \mathrm{Ba}^{*}$ & $0,71 \mathrm{Ba}^{*}$ & $0,63 \mathrm{Ab}^{*}$ & $0,66 \mathrm{~B}$ \\
\hline DKB 599 & $0,65 \mathrm{Ab}$ & $0,63 \mathrm{Ab}$ & $0,78 \mathrm{Aa}^{*}$ & $0,80 \mathrm{Aa}$ & $0,62 \mathrm{Ab}^{*}$ & $0,69 \mathrm{~A}$ \\
\hline Médias & $0,62 \mathrm{~b}$ & $0,63 \mathrm{~b}$ & $0,76 \mathrm{a}$ & $0,76 \mathrm{a}$ & $0,62 \mathrm{~b}$ & \\
\hline Monocultivo & $0,65 \mathrm{c}$ & $0,66 \mathrm{c}$ & $0,84 \mathrm{a}$ & $0,78 \mathrm{~b}$ & $0,68 \mathrm{c}$ & \\
\hline \multicolumn{7}{|c|}{ IPB $\left(n^{\circ}\right.$ perfilhos planta $\left.{ }^{-1}\right)$} \\
\hline BRS 310 & $14,8^{*}$ & $12,5^{*}$ & 12,7 & 13,3 & $16,9 *$ & 14,0 \\
\hline DKB 599 & $12,8^{*}$ & $12,8^{*}$ & 11,4 & 14,8 & $18,2^{*}$ & 14,0 \\
\hline Médias & $13,8 \mathrm{ab}$ & $12,6 \mathrm{~b}$ & $12,0 \mathrm{~b}$ & $14,1 \mathrm{ab}$ & $17,6 \mathrm{a}$ & \\
\hline Monocultivo & $21,5 \mathrm{~b}$ & $23,4 \mathrm{~b}$ & $10,0 \mathrm{~d}$ & $15,5 \mathrm{c}$ & $28,1 \mathrm{a}$ & \\
\hline \multicolumn{7}{|c|}{$\mathrm{C} / \mathrm{N}$} \\
\hline BRS 310 & $23,7 \mathrm{Aa}$ & $18,2 \mathrm{Bb}$ & $22,2 \mathrm{Aa}$ & $24,2 \mathrm{Aa}$ & $22,6 \mathrm{Aa}$ & 22,1 \\
\hline DKB 599 & $23,5 \mathrm{Aa}$ & $22,5 \mathrm{Aab}$ & $23,7 \mathrm{Aa}$ & $21,2 \mathrm{Ab}^{*}$ & $16,8 \mathrm{Bc}^{*}$ & 21,5 \\
\hline Médias & $23,6 \mathrm{a}$ & $20,4 \mathrm{ab}$ & $23,0 \mathrm{a}$ & $22,8 \mathrm{ab}$ & $19,7 \mathrm{~b}$ & \\
\hline Monocultivo & $25,8 \mathrm{ab}$ & $22,4 \mathrm{~b}$ & $22,2 \mathrm{~b}$ & $28,6 \mathrm{a}$ & $22,7 \mathrm{~b}$ & \\
\hline
\end{tabular}

${ }^{\text {/1}}$ : Médias seguidas pela mesma letra maiúscula na coluna e minúscula na linha não diferem entre si pelo teste de Tukey a 5\% de probabilidade.

* Média difere significativamente pelo teste de Dunnett a 5\% de probabilidade em relação ao monocultivo de braquiária.

Fonte: Elaboração dos autores.

Dentre as espécies utilizadas, observou-se que a B. ruziziensis foi a que apresentou maior capacidade de perfilhamento (maiores valores no consórcio e no monocultivo) (Tabela 3). Em contrapartida, a $B$. brizantha cv. Piatã e Marandu no consórcio e a $B$. brizantha cv. Piatã no monocultivo foram as que apresentaram menores índices de perfilhamento. Quando comparado aos respectivos monocultivos de braquiária, o consórcio com sorgo, independente do híbrido, ocasionou reduções no perfilhamento da $B$. brizantha cv. Xaraés e cv. Marandu, além da $B$. ruziziensis. A interceptação da radiação solar pelo dossel das plantas de sorgo fez com que houvesse menor incidência de radiação direta na parte basal das plantas de braquiária (LARCHER, 2003), ocasionando assim supressão do perfilhamento das gemas axilares da forrageira (MATTHEW et al., 2000).

Quanto a relação C/N das espécies de braquiária, observou-se variação em função da associação com o sorgo (Tabela 3). Somente o consórcio do BRS 
310 com a $B$. brizantha cv. Marandu apresentou valor inferior em relação às demais combinações, o mesmo sendo observado para o DKB 599 consorciado com a $B$. ruziziensis. Em monocultivo a $B$. decumbens apresentou maior relação $\mathrm{C} / \mathrm{N}$, diferindo da $B$. brizantha cv. Marandu, cv. Piatã e $B$. ruziziensis. Os resultados obtidos com as braquiárias são superiores aos de outros trabalhos de pesquisa com a $B$. brizantha 16,1 e 19,6; (TORRES et al., 2005), cv. Xaraés 12,0; (RODRIGUES et al., 2007) e inferiores para a $B$. ruziziensis 40,8; (MENEZES; LEANDRO, 2004).

A maior relação $\mathrm{C} / \mathrm{N}$ da massa seca da braquiária, obtida no período da entressafra em condições de cerrado, torna-se vantajosa para manter por mais tempo a superfície do solo coberta (KLIEMANN; BRAZ; SILVEIRA, 2006; BORGHI; CRUSCIOL, 2007). Destaca-se que a determinação desta variável foi realizada aos 131 dias após a colheita do sorgo, ou seja, próximo ao período de implantação da soja. A maior permanência da massa seca na superfície do solo na fase inicial de desenvolvimento da cultura propicia a proteção do solo contra erosão, visto que nesta fase a soja não possibilita uma cobertura efetiva do solo, além de exercer supressão na emergência das ervas daninhas (MENEZES; LEANDRO, 2004; KLIEMANN; BRAZ; SILVEIRA, 2006; MACHADO et al., 2011).

\section{Culturas do sorgo e braquiária}

A análise de variância para o rendimento de massa seca, proteína bruta total e cobertura do solo permitiu constatar significâncias para as fontes de variação Monocultivo e Consórcio x Monocultivo, além da interação Sorgo x Braquiária para as variáveis rendimento de massa seca total e índice de eficiência de área (Tabela 1).

$\mathrm{Na}$ avaliação do desempenho dos sorgos no consórcio, constatou-se que o híbrido BRS 310 proporcionou maior rendimento de massa seca total quando comparado ao DKB 599 nas associações com a $B$. brizantha cv. Xaraés e B. ruziziensis, não havendo diferenças para as demais espécies (Tabela 4). Para o BRS 310, o maior valor foi obtido com o consórcio da B. ruziziensis, superando as associações com as $B$. brizantha $\mathrm{cv}$. Marandu e cv. Piatã, além da $B$. decumbens. Em relação ao DKB 599, não foram observadas diferenças expressivas para a variável em questão.

A implantação do ensaio no final de fevereiro, associada à diminuição da distribuição de chuvas nos meses subsequentes (Figura 1), provavelmente, limitaram o estabelecimento e o desenvolvimento das plantas de braquiária no consórcio e em monocultivo. Consequentemente, houve menor rendimento de massa seca na entressafra comparado a outros trabalhos de pesquisa com consórcio com milho e $B$. brizantha cv. Marandu na safrinha (com rendimento médio de, aproximadamente, $3.500 \mathrm{~kg}$ $\mathrm{ha}^{-1}$ ) (BORGHI, CRUSCIOL, 2007; EUCLIDES et al. 2008; BRAMBILLA et al., 2009). Sabe-se que a antecipação em um mês da época de semeadura do milho em relação ao sorgo na safrinha na região Centro-Oeste propicia o melhor aproveitamento de chuvas (CRUZ et al., 2010), possibilitando maior desenvolvimento das plantas de braquiária quando consorciadas com milho.

$\mathrm{Na}$ comparação do rendimento de massa seca do consórcio com os do monocultivo, constatou-se que as associações do BRS $310 \mathrm{com}$ a $B$. brizantha cv. Xaraés e $B$. ruziziensis foram as que apresentaram os maiores valores em relação ao monocultivo do sorgo (Tabela 4), comprovando o incremento de massa seca pelas plantas de braquiárias. O desempenho superior no consórcio deve-se ao fato de que o sorgo foi colhido em julho e as braquiárias tiveram um período adicional de 131 dias para desenvolvimento na entressafra antes de serem cortadas, resultando em maior acúmulo de biomassa. 
Tabela 4. Valores médios de rendimentos de matéria seca (RMST) e proteína bruta total (RPBT), cobertura do solo (CS) e índice de equivalência de área (IEA) do consórcio na linha dos sorgos graníferos BRS 310 e DKB 599 com $B$. brizantha cv. Xaraés (Xaraés), cv. Marandu (Marandu) e cv. Piatã (Piatã), B. decumbens (Bd) e B. ruziziensis $(B r)$ na safrinha, Rio Verde-GO ${ }^{1 /}$.

\begin{tabular}{|c|c|c|c|c|c|c|}
\hline Consórcio & Xaraés & Marandu & Piatã & $B d$ & $\mathrm{Br}$ & Média \\
\hline \multicolumn{7}{|c|}{ RMST $\left(\mathrm{kg} \mathrm{ha}^{-1}\right)$} \\
\hline BRS 310 & $1.093 \mathrm{Aab}^{* 1}$ & $819 \mathrm{Abc}$ & $780 \mathrm{Ac}^{* 3}$ & $966 \mathrm{Abc}^{* 3}$ & $1.284 \mathrm{Aa}^{* 1,2}$ & 988 \\
\hline DKB 599 & $842 \mathrm{Ba}^{* 3}$ & $841 \mathrm{Aa}$ & $853 \mathrm{Aa}^{* 3}$ & $1.078 \mathrm{Aa}^{* 1}$ & $923 \mathrm{Ba}$ & 907 \\
\hline Média & 967 & 830 & 816 & 1.022 & 1.104 & \\
\hline \multicolumn{7}{|c|}{ Monoculivo } \\
\hline Xaraés & Marandu & Piatã & $B d$ & $B r$ & BRS 310 & DKB 599 \\
\hline $1.328 \mathrm{a}$ & $1.104 \mathrm{abc}$ & $968 \mathrm{bcd}$ & $1.279 \mathrm{ab}$ & $1.350 \mathrm{a}$ & $680 \mathrm{~d}$ & $825 \mathrm{~cd}$ \\
\hline \multicolumn{7}{|c|}{ RPBT $\left(\mathrm{kg} \mathrm{ha}^{-1}\right)$} \\
\hline BRS 310 & $105^{* 1,2}$ & $107 * 1,2$ & 87 & $102 * 1,2,3$ & $129 * 1,2,3$ & 106 \\
\hline DKB 599 & $88^{* 3}$ & $104 * 1,2$ & $92 * 1$ & $123^{* 1,2}$ & $143^{* 1,2,3}$ & 110 \\
\hline Média & 97 & 105 & 90 & 112 & 136 & \\
\hline \multicolumn{7}{|c|}{ Monoculivo } \\
\hline Xaraés & Marandu & Piatã & $B d$ & $\mathrm{Br}$ & BRS 310 & DKB 599 \\
\hline $150 \mathrm{~b}$ & $137 \mathrm{~b}$ & $123 \mathrm{~b}$ & $159 \mathrm{~b}$ & $226 \mathrm{a}$ & $32 \mathrm{c}$ & $44 \mathrm{c}$ \\
\hline \multicolumn{7}{|c|}{ CS (\%) } \\
\hline BRS 310 & $45,8 * 3$ & $49,2 * 3$ & $40,0 * 2,3$ & $44,2 * 3$ & $48,3^{* 3}$ & $45,5 \mathrm{~B}$ \\
\hline DKB 599 & $50,0 * 3$ & $50,0 * 3$ & $42,5^{* 2,3}$ & 51,7 & 52,5 & $49,3 \mathrm{~A}$ \\
\hline Média & $47,9 \mathrm{ab}$ & $49,6 \mathrm{a}$ & $41,2 \mathrm{~b}$ & $47,9 \mathrm{ab}$ & $50,4 \mathrm{a}$ & \\
\hline & & & Monoculivo & & & \\
\hline Xaraés & Marandu & Piatã & $B d$ & $B r$ & BRS 310 & DKB 599 \\
\hline $60,8 \mathrm{a}$ & $59,2 \mathrm{ab}$ & $50,8 \mathrm{bcd}$ & $54,2 \mathrm{abc}$ & $58,3 \mathrm{ab}$ & $45,8 \mathrm{~d}$ & $50,0 \mathrm{~cd}$ \\
\hline \multicolumn{7}{|c|}{ IEA } \\
\hline BRS 310 & 1,45 Aab & 1,26 Aab & $1,25 \mathrm{Aab}$ & $1,06 \mathrm{Ab}$ & 1,64 Aa & 1,33 \\
\hline DKB 599 & $1,08 \mathrm{Aa}$ & 1,11 Aa & $1,27 \mathrm{Aa}$ & 1,41 Aa & $1,15 \mathrm{Ba}$ & 1,20 \\
\hline Média & 1,27 & 1,19 & 1,26 & 1,24 & 1,40 & \\
\hline
\end{tabular}

${ }^{\prime \prime}$ : Médias seguidas pela mesma letra maiúscula na coluna e minúscula na linha não diferem entre si pelo teste de Tukey a $5 \%$ de probabilidade.

$*^{* 1}, *^{2},{ }^{* 3}$ : Média difere significativamente pelo teste de Dunnett a 5\% de probabilidade em relação aos sorgos graníferos BRS 310 e DKB 599 e das espécies de braquiárias, respectivamente.

Fonte: Elaboração dos autores.

Entretanto, não foram constatadas diferenças significativas do rendimento de massa seca entre os sistemas de cultivo para o DKB 599 (Tabela 4). A ausência de significância está no fato de que a menor disponibilidade de água no solo, durante o crescimento das plantas na safrinha (CRUZ et al., 2010), limitou a obtenção de incrementos significativos de biomassa no consórcio. Devido à competição com as plantas de sorgo, a $B$. brizantha cv. Piatã, independente do híbrido consorciado, a $B$. decumbens consorciada com o BRS 310 e a B. brizantha cv. Xaraés com o DKB 599 foram as associações que apresentaram menores rendimentos de massa seca em comparação aos respectivos monocultivos de braquiária. Neste sistema a $B$. ruziziensis destacou-se das demais e os híbridos de sorgo foram os de menor rendimento de massa seca.

O consórcio proporcionou também vantagens na produção de proteína bruta total. Todas as associações do BRS 310 com as braquiárias, exceto com a $B$. brizantha cv. Piatã, apresentaram maiores valores em relação ao monocultivo do sorgo (Tabela 4). Para o DKB 599, isto foi observado com a $B$. brizanthacv. Marandu, B. decumbens e B. ruziziensis. 
Nas demais associações de sorgo e braquiária, não foram constatadas diferenças significativas entre os sistemas de cultivo, porém tem-se a vantagem de se produzir biomassa de braquiária no consórcio. Quando comparado aos monocultivos das espécies de braquiária, destacam-se os consórcios dos sorgos com a $B$. brizantha cv. Marandu e Piatã, além do BRS 310 com a $B$. brizantha cv. Xaraés e do DKB 599 com a $B$. decumbens, cujos valores não diferiram entre os sistemas de cultivo. Isto demonstra o potencial destas associações para produção de proteína bruta na entressafra nas condições de cerrado (MACHADO; ASSIS, 2010).

A avaliação do percentual de cobertura do solo permitiu constatar resultados diferenciados no consórcio (Tabela 4). Neste sistema os resultados foram semelhantes aos do monocultivo de sorgo, exceto para o DKB 599 consorciado com a $B$. brizantha cv. Piatã, no qual apresentou menor valor. Em comparação aos monocultivos da braquiária, destacam-se os consórcios da $B$. decumbens e B. ruziziensis com o DKB 599, cujos resultados não diferiram entre o consórcio e o monocultivo. Ressalta-se que esta variável foi determinada após a colheita do sorgo e no momento do corte das plantas de braquiária (131 dias após a colheita do sorgo), toda a superfície do solo estava coberta, o que demonstra o potencial da forrageira para estes fins (MACHADO; ASSIS, 2010). Em monocultivo a melhor performance foi obtida com a $B$. brizantha cv. Xaraés e a menor com os sorgos, como observado por Timossi, Durigan e Leite. (2007).

A análise do IEA permitiu comprovar novamente a vantagem do consórcio sorgo granífero e braquiária na safrinha, pois todos resultados foram superiores a um (Tabela 4). Os consórcios do BRS 310 com a $B$. ruziziensis e $B$. brizantha cv. Xaraés, além do DKB 599 com a $B$. decumbens, foram os que apresentaram maiores valores de IEA, atribuídos aos maiores rendimentos de grãos e massa seca. Outros trabalhos de pesquisa constataram vantagens da produção de massa seca (forragem) quando híbridos de sorgo forrageiro foram consorciados com soja (SILVA et al., 2000; REZENDE et al., 2004).

Portanto os resultados obtidos demonstram a viabilidade do consórcio sorgo granífero e braquiária para produção de grãos e palhada/ forragem (massa seca e proteína bruta) na safrinha na região Centro-Oeste. $O$ consórcio possibilitou a produção de forragem durante a estação seca do ano, época em que as pastagens encontram-se debilitadas para pastejo. Caso o produtor associe a criação de gado com a produção de grãos, com formação de cobertura vegetal sobre o solo, é necessário interromper o pastejo dos animais antes da implantação da cultura de verão, visando aumento da biomassa na área. Posteriormente, esta biomassa será dessecada para formação de palhada (cobertura vegetal) para implantação da soja. Sendo assim o produtor maximiza os ganhos com a atividade agrícola explorando, de forma racional e sustentável, a integração lavoura-pecuária em solos cultivados no sistema plantio direto na região Centro-Oeste.

\section{Conclusões}

O consórcio de sorgo e braquiária, na safrinha, mostrou-se como técnica de cultivo viável para produção de grãos e palhada na região CentroOeste.

O sorgo BRS 310 consorciado com a $B$. ruziziensis e $B$. brizantha cv. Xaraés possibilitaram maiores rendimentos de grãos, massa seca e proteína bruta total, sendo o mesmo observado para o DKB 599 consorciado com a B. decumbens.

O DKB 599, de maior potencial produtivo em monocultivo, apresentou maior sensibilidade a competição com as plantas de braquiária no consórcio. 


\section{Agradecimentos}

Ao Conselho Nacional de Desenvolvimento Científico e Tecnológico-CNPq, pelo auxílio financeiro na realização do trabalho e pela concessão da bolsa de produtividade em pesquisa.

\section{Referências}

BAUMHARDT, R. L.; TOLK, J. A.; WINTER, S. R. Seeding practices and cultivar maturity effects on simulated dryland grain sorghum yield. Agronomy Journal, Madison, v. 97, n. 3, p. 935-942, 2005.

BORGHI, E.; CRUSCIOL, C. A. C. Produtividade de milho, espaçamento e modalidade de consorciação com Brachiaria brizantha em sistema plantio direto. Pesquisa Agropecuária Brasileira, Brasília, v. 42, n. 2, p. 163-171, 2007.

BRAMBILlA, J. A.; LANGE, A.; BUCHELT, A. C.; MASSAROTO, J. A. Produtividade de milho safrinha no sistema de integração lavoura-pecuária, na região de sorriso, Mato Grosso. Revista Brasileira de Milho e Sorgo, Sete Lagoas, v. 8, n. 3, p. 263-274, 2009.

CALVO, C. L.; FOLONI, J. S. S.; BRANCALIÃO, S. R. Produtividade de fitomassa e relação $\mathrm{C} / \mathrm{N}$ de monocultivos e consórcios de guandu-anão, milheto e sorgo em três épocas de corte. Bragantia, Campinas, v. 69, n. 1, p. 77-86, 2010.

CRUZ, J. C.; SILVA, G. H.; PEREIRA FILHO, I. A.; GONTIJO NETO, M. M.; MAGALHÃES, P. C. Caracterização do cultivo de milho safrinha de alta produtividade em 2008 e 2009. Revista Brasileira de Milho e Sorgo, Sete Lagoas, v. 9, n. 2, p. 177-188, 2010.

DAN, H. A.; CARRIJO, M. S.; CARNEIRO, D. F.; COSTA, K. A. P.; SILVA, A. G. Desempenho de plantas sorgo granífero sobre condições de sombreamento. Acta Scientiarum Agronomy, Maringá, v. 32, n. 4, p. 675-679, 2010.

EMPRESA BRASILEIRA DE PESQUISA AGROPECUÁRIA - EMBRAPA. Centro Nacional de Pesquisa de Solos. Manual de métodos de análise de solo. 2. ed. Rio de Janeiro: EMBRAPA-CNPS, 1997. 212 p.

EUCLIDES, V. P. B.; MACEDO, M. C. M.; VALLE, C. B.; BARBOSA, R. A.; GONÇALVES, W. V. Produção de forragem e características da estrutura do dossel de cultivares de Brachiaria brizantha sob pastejo. Pesquisa Agropecuária Brasileira, Brasília, v. 43, n. 12, p. 18051812, 2008.
KLIEMANN, H. J.; BRAZ, A. J. P. B.; SILVEIRA, P. M. Taxas de decomposição de resíduos de espécies de cobertura em latossolo vermelho distroférrico. Pesquisa Agropecuária Tropical, Goiânia, v. 36, n. 1, p. 21-28, 2006.

LARCHER, W. Physiological plant ecology: ecophysiology and stress physiology of functional groups. Berlin: SPRINGER, 2003. 513 p.

MACHADO, L. A. Z.; ASSIS, P. G. G. Produção de palha e forragem por espécies anuais e perenes em sucessão à soja. Pesquisa Agropecuária Brasileira, Brasília, v. 45, n. 4, p. 415-422, 2010.

MACHADO, V. D.; TUFFI SANTOS, L. D.; SANTOS JUNIOR, A.; MOTA, V. A.; PADILHA, S. V.; SANTOS, M. V. Fitossociologia de plantas daninhas em sistemas de integração de sorgo com braquiária sob diferentes formas de implantação da pastagem. Planta Daninha, Viçosa, MG, v. 29, n. 1, p. 85-95, 2011.

MALAVOLTA, E.; VITTI, G. C.; OLIVEIRA, S. A. Avaliação do estado nutricional de plantas: princípios e aplicações. 2 ed. Piracicaba: POTAFOS, 1997. 319 p.

MATTHEW, C.; ASSUERO, S. G.; BLACK, C. K.; HAMILTON, N. R. S. Tiller dynamics of grazed swards. In: LEMAIRE, G.; HODGSON, J.; MORAES, A.; CARVALHO, P. C. F.; NABINGER, C. (Ed.). Grassland ecophysiology and grazing ecology. Wallingford: CABI Publishing, 2000. p. 127-150.

MELLO, L. M. M.; YANO, É. H.; NARIMATSU, K. C. P.; TAKAHASHI, C. M.; BORGHI, É. Integração agricultura-pecuária em plantio direto: produção de forragem e resíduo de palha após pastejo. Engenharia Agricola, Jaboticabal, v. 24, n. 1, p. 121-129, 2004.

MENEZES, L. A. S.; LEANDRO, W. M. Avaliação de espécies de coberturas do solo com potencial de uso em sistema de plantio direto. Pesquisa Agropecuária Tropical, Goiânia, v.34, n. 3, p.173-180, 2004.

REZENDE, P. M.; SILVA, A. G.; BOTREL, É. P.; GOMES, L. L.; GRIS, C. F. Consórcio sorgo-soja. VIII. Sistema de corte, cultivares de soja e híbridos de sorgo na produção de forragem das culturas consorciadas na entrelinha e monocultivo do sorgo. Revista Brasileira de Agrociência, Pelotas, v. 10, n. 4, p. 475-481, 2004.

RODRIGUES, R. C.; MOURÃO, G. B.; VALINOTE, A. C.; HERLING, V. R. Reservas orgânicas, relação parte aérea-raiz e C-N e eliminação do meristema apical no capim-xaraés sob doses de nitrogênio e potássio. Ciência Animal Brasileira, Goiânia, v. 8, n. 3, p. 505-514, 2007.

SILVA, A. G.; REZENDE, P. M.; CORTE, E.; MANN, E. N. Consórcio sorgo-soja. III. Seleção de cultivares de 
sorgo e soja, consorciadas na linha, visando à produção de forragem. Ciência e Agrotecnologia, Lavras, v. 24, n. 4, p. 861-868, 2000.

SILVA, A. G.; BARROS, A. S.; SILVA, L. H. C. P.; MORAES, E. B.; PIRES, R.; TEIXEIRA, I. R. Avaliação de cultivares de sorgo granífero na safrinha no sudoeste do Estado de Goiás. Pesquisa Agropecuária Tropical, Goiânia, v. 39, n. 2, p. 168-174, 2009a.

SILVA, P. C. G.; FOLONI, J. S. S.; FABRIS, L. B.; TIRITAN, C. S. Fitomassa e relação $\mathrm{C} / \mathrm{N}$ em consórcios de sorgo e milho com espécies de cobertura. Pesquisa Agropecuária Brasileira, Brasília, v. 44, n. 11, p. 15041512, 2009b.

SOUZA, C. N.; SOUZA, I. F.; PASQUAL, M. Extração e ação do sorgoleone sobre o crescimento das plantas. Ciência e Agrotecnologia, Lavras, v. 23, n. 2, p. 331-338, 1999.
TIMOSSI, P. C.; DURIGAN, J. C.; LEITE, G. J. Formação de palhada por braquiárias para adoção do sistema plantio direto. Bragantia, Campinas, v. 66, n. 4, p. 617-622, 2007.

TORRES, J. L. R.; PEREIRA, M. G.; ANDRIOLI, I.; POLIDORO, J. C.; FABIAN, A. J. Decomposição e liberação de nitrogênio de resíduos culturais de plantas de cobertura em um solo de cerrado. Revista Brasileira de Ciência do Solo, Viçosa, MG, v. 29, n. 4, p. 609-618, 2005.

VILELA, L.; SOARES, W. V.; SOUSA, D. M. G.; MACEDO, M. C. M. Calagem e adubação para pastagens na região do cerrado. Planaltina: EMBRAPACPAC. 1998. 16 p. (Circular técnica, 37). 